\title{
Study on Innovative Use of Resources
}

\author{
Xin Zhang \\ Guang Dong University of Technology. \\ 16833228@qq.com
}

Keywords: Product design,resources,sustainable development.

\begin{abstract}
Resources not only mean natural resources, but those hidden within a system itself. By reasonable approaches, the human society can make full use of resources within systems and achieve optimal use of resources. This paper introduces to product design the idea of resource analysis, i.e., an analysis of the internal and external resources in a system. By real-world examples, this paper intends to demonstrate that resource analysis is really critical to help designer to design products that are most resource efficient.
\end{abstract}

\section{Introduction}

The word "resource" primarily refers to natural resources, including water, land, lumber and mines. Abundant natural resources are key to the prosperity of a nation or region. As time goes by, many scholars find that resources are not limited to natural resources only. They put forward the notion of differential resource, variable resource, revolutionary resource, and among others. However, many resources in a system are hidden, because most of the noticeable ones have been utilized.

In product design, designers generally utilize resources to solve a problem, but one of their concerns is how to minimize the use of resources and how to make full use of resources already available in a system. Saving resources and cutting costs are a lasting human pursuit. This paper is intended to explore how to find resources we need, how to optimize the use of resources, and how to utilize resources in product design.

\section{Classification of Resources \& Utilization of Renewable Resources}

Classification I: Resources can be classified as directly usable resources, differential resources, and derived resources as per their way of being used. Directly usable resources refer to resources that can be utilized in their present state of existence. For example, materials, fields, energy and space are all under this category. We use lumber to cook, coal to generate power, and polar fields to make our compass work. These are all directly usable resources. Differential resources refer to resources of technical nature formed as a result of the different characteristics of material and filed. This category includes differential material resources and differential field resources.

Derived resources are found in cases of a transformation, which enables unusable resources to produce usable resources. Usable resources obtained in this manner are called derived resources. We can convert unusable resources to usable ones by means of a transformation, and also obtain field resources by changing the strength and direction of action and other properties. For example, lighting is a form of high-power resource, but we are unable to use it. We can invent an apparatus which can store lighting power and transform it into stable power. Also, we can alter an ordinary magnetic filed to a rotating one so as to make better use of it.

Category II: Resources can be classified as material resources, field resources, space resources, time resources, information resources and function resources as per their form of presence.

Material resources refer to systems and their related elements, materials, products, components, wastes, and other things that can be used. Field resources include mechanical energy, vibrational energy, heat, chemical energy, electric energy, light, and other forms of radiant energy. Energy of these different forms areinterconvertible. Space resources include system and environment resources. Such resources can be used to place new objects or solve the problem of space shortage. 
Time resources refer to utilizable time intervals, for example, time prior to the start of a process, time while a process is taking place, and time for pause and standby mode. Simultaneity of different processes and process acceleration both can save time. For example, transportation and refining of crude oil are extremely time-consuming. To save time, a refining machine can be installed on a crude oil carrier, so that the oil is refined during the long journey of transportation. Parallel processes save a great deal of time. Also, the process of a CNC milling machine moving between spaces and processing is usually accelerated to save time.

Information resource refers to all the information in a system and its environment in the present state. It includes information of change of a system and its environment, for instance, the field made by a system and its elements, substances beyond a system, the properties of a system and its elements (temperature, transparency, natural frequency, etc.), and change of energy flow through a system and its primary colors. For example, a machine will generate a weak sound wave if something breaks down in it. This can be used to check early malfunctions.

Function resources can be defined as the capacity of a system and its environment to execute additional functions. For example, a system and its environment can assist in the execution of beneficial functions, convert hazardous functions to beneficial ones, and help combine and consolidate executable functions. "Reactive armor" for tank is a good example of converting a hazardous function to a beneficial one. Reactive armor is actually inert explosives loaded on the armor of a tank. If bullets or small shells hit the tank, the explosives will not react. But they will explode outward in the case of shaped charge warheads and other weapons that can penetrate armors. This can significantly weaken the destruction from anti-tanks.

\section{How to Apply Resource Analysis to Problems in Product Design}

Energy is an important issue facing the human society. With the rapid consumption of oil, coal, natural gas and other non-renewable energy, greenhouse effect triggered by such consumption, and carbon dioxide emissions and other environmental problems, the development and utilization of new energy has drawn more and more attention from the international community. Product invariably involves use of renewable energy, so it is essential for us to understand the present situation and prospects of use of renewable energy such as biomass energy, solar energy, wind energy, geothermal energy, nuclear energy and hydrogen energy.

Biomass energy holds the fourth place in the world's total energy, only next to coal, oil and natural gas. In rural areas, biomass energy is used to produce methane, a clear gas fuel, which fundamentally improves the lives of rural residents. Solar energy is used primarily for solar water heater and power generation, and it is a type of energy that can be utilized on massive scale. Solar cells can convert solar energy directly to electric power. Wind energy is rich and renewable, and wind power is free from fuel, radiation or carbon dioxide emission. Wind power equipment is over $90 \%$ cheaper than its solar counterpart. If wind energy is properly utilized, environmental pollution is reduced on the one hand, and the tension caused by increasingly severe energy shortage is relieved on the other. Water energy is renewable. It is shown in the form of river flows, ocean tides, waves, ocean currents, and so on. Geothermal energy is renewable heat from the depth of the earth. Geothermal energy is stored in the rocks or fluids in the earth and can be utilized by small thermal power plant. Nuclear power generation produces only small amounts of carbon dioxide, but it is safer and more cost-effective. Hydrogen energy is generally acknowledged as a clear energy. It comes from a variety of sources and is most likely to replace biofuels in the future.

After learning about what resource is and its categories, we will realize that there are too many resources around us that are readily available but have not been fully utilized. This also affects creative product designs and conservation of resources. In order to make better use of resources, we have to observe what resources have not been utilized, to what extent they have been utilized, or what other possibilities of resources in a system are. But how can we make better use of resources in product design? Here is a guideline: First, we should make clear what problem(s) we are trying to solve. Then think about in what order we are going to look for resources in a system, how to optimize the use of these resources, and how to utilize such resources in product design. 
Resources can be found in the current system, supersystem and subsystem. Current system is the system that the product concerned is in. Supersystem refers to systems related to the product concerned. Subsystem refers to the systems of product parts and elements. The search for resources can be conducted in such a manner that covers the present, past and future of the current system, its subsystems and supersystems.

Principles of using resources: choose resources with the least consumption. The best order of choosing resources is internal system resources, then external system resources, and lastly overall system and revolutionary resources. It is suggested that we should always expand our scope of search in order to solve problems, and try to find as many alternative resources as possible.

\section{Instance Analysis: Power of LED Road Block}

Problem Description: Road block aims to warn people to protect their own lives and those of others. It is small, light, cheap, flexible, and easy to carry. In case of night driving, particularly on a motorway, or breakdowns, dangerous items near the driveway, natural disasters, rescues, and construction underway, road blocks are always used to warn passing vehicles of the danger and take protective measures.

Ordinary road block generally work, but in case of rain, fog or poor-visibility weather, an LED road block (see Figure 1), which can produce patterns by swaying or rotating LED light bars, works better (see Figure 2). This road block needs power because of its LED light bars. Without enough power, it will not work. However, car accidents often happen on the motorway or outdoor where continuous power supply is unavailable. The popular solution is to use battery or get it connected with the cigarette lighter. There is another problem, though. Even if the battery is fully charged, but due to long period of disuse, it is likely to have no power at all when the accident happens. If external power supply is to be used, a long wire is needed, which is surely not so readily available.

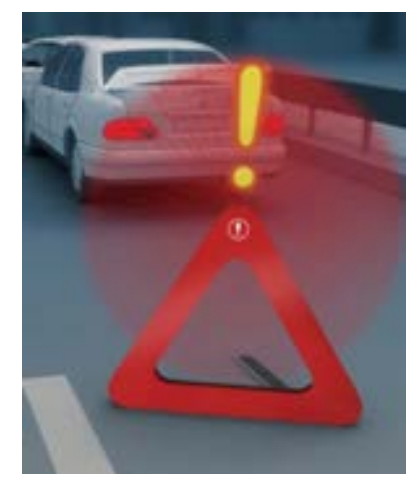

Fig. 1 LED road block at work

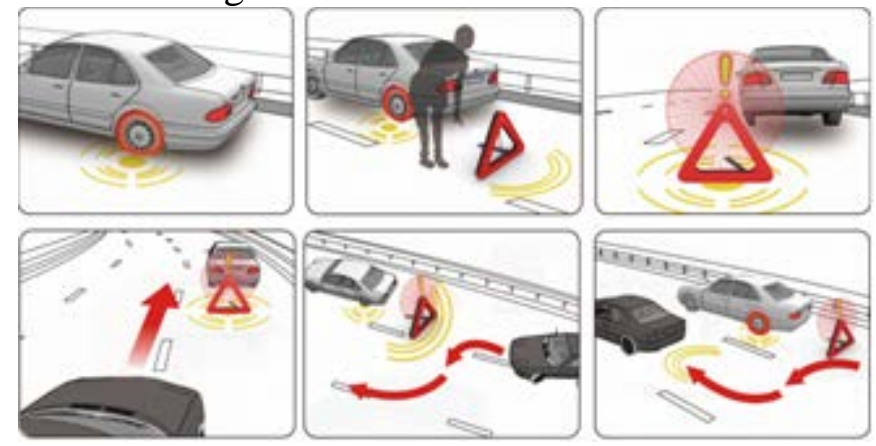

Fig. 2How to Use LED Road Block

A Resource Analysis Approach to This Problem.Resources within the System: (1) Material resource: car body shell, motor structure within the car, interior decorations and cushions, air, automobile exhaust;(2)Field resource: mechanical energy of gasoline burning, heat, electric energy of cigarette lighter, mechanical energy of closing hood, shake of car while running, heat of automobile exhaust, gravity;(3) Space resource: car interior, car trunk, car bottom, interior of car front hood;(4) Information resource: GPS, radio, CD player, parking sensor and stereo systems, 
DVD player, automobile intercom system. (5)Function resource: refrigeration, heating, driving, video, music, parking.Resources out of the System:(1) Material resource: air, exhaust, motorway, trees, guardrail;(2) Field resource: pressure of a running car on road, aerodynamic, gravity, solar energy;(4)Space resource: open natural world.

After a close study, it is found that the possible sources of power for an LED road block include mechanical energy of closing car hood, shaking of car while running, and pressure of a running car on road. The first and third solutions require more complicated devices, so the best source of power supply is shaking of car while running (see Table 1).

Table 1 LED Road Block Power Devices comparing

\begin{tabular}{|c|c|c|c|c|}
\hline Devices & Mannerof Working & Power & $\begin{array}{l}\text { Environmental } \\
\text { Performance }\end{array}$ & Ratings \\
\hline Oscillatingmagnetic power device & $\begin{array}{c}\text { Move } \\
\text { fromsidetoside }\end{array}$ & Low & $\begin{array}{l}\text { Eco-friendly; } \\
\text { greenenergy }\end{array}$ & \\
\hline Piezoelectricvibration power device & $\begin{array}{l}\text { Move orvibrate in } \\
\text { multiple directions }\end{array}$ & Moderate & $\begin{array}{l}\text { Eco-friendly; } \\
\text { greenenergy }\end{array}$ & \\
\hline $\begin{array}{c}\text { Swinging micro power device } \\
\text { Swi }\end{array}$ & $\begin{array}{c}\text { Move orvibrate in } \\
\text { anydirection }\end{array}$ & High & $\begin{array}{l}\text { Eco-friendly; } \\
\text { greenenergy }\end{array}$ & \\
\hline
\end{tabular}

For the first one, oscillating magnetic power device, power is generated because there is a closed traverse cutting magnetic induction lines. But power generated in this case is too little to supply the light. For the second one, piezoelectric vibration power device, a closed traverse cuts the magnetic induction lines vertically and with vibration, but the output is also too little to supply enough power. For the third one, swinging of pendulum is made use of to drive micro generator, and the power generated is enough to supply the light. These are a few ways how mechanical energy can be converted to electric power. The comparison shows that the third solution has a higher conversion rate. Therefore, the third power device is chosen (see Figure 3).
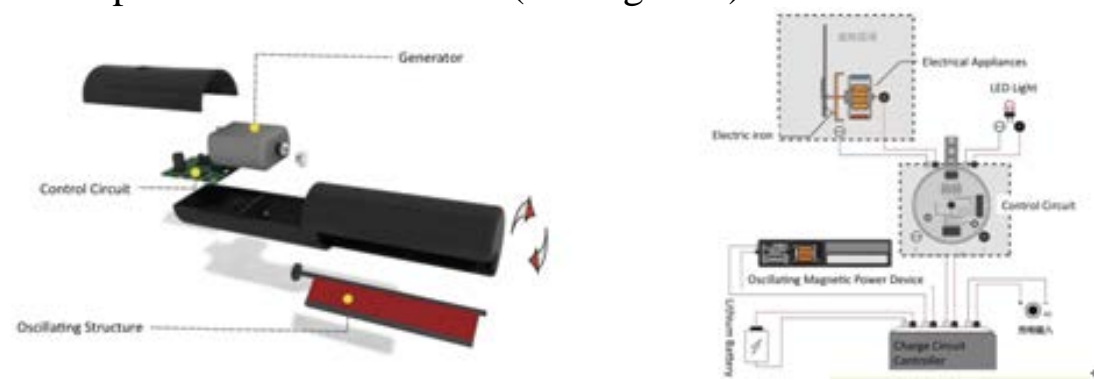

Fig 3. Exploded View and Circuit Diagram of Swinging Micro Generator

This swimming ring is an award-winning work designed by students from Taiwan. A device that can convert tidal energy to electric power is installed in it, so the swimming ring can be heated up when necessary to prevent death of cold. It leaves a great deal of time for rescue. This design is a good example of how external resources can be put to better use (Figure 4).

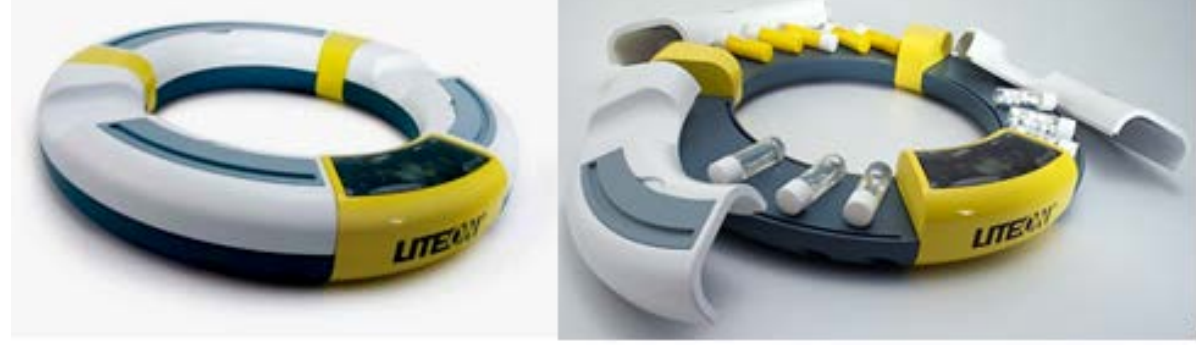

Fig 4. Tidal Energy-Based Swimming Ring 
This work won the gold medal in Taiwan Lite-On Award. "Green Pass” is basically a three-roller pass designed for heavy-traffic public areas. This design features a built-in energy conversion device, which can collect the energy people consume when passing a three-roller pass, convert it to electric power and store it in battery. It is a process where mechanical energy is converted to electric power. The power generated can supply the instantaneous power consumption of LED display panel. In this way, the three-roller pass is genuinely energy self-sufficient, zero power consumption, zero pollution and zero emission (Figure 5).
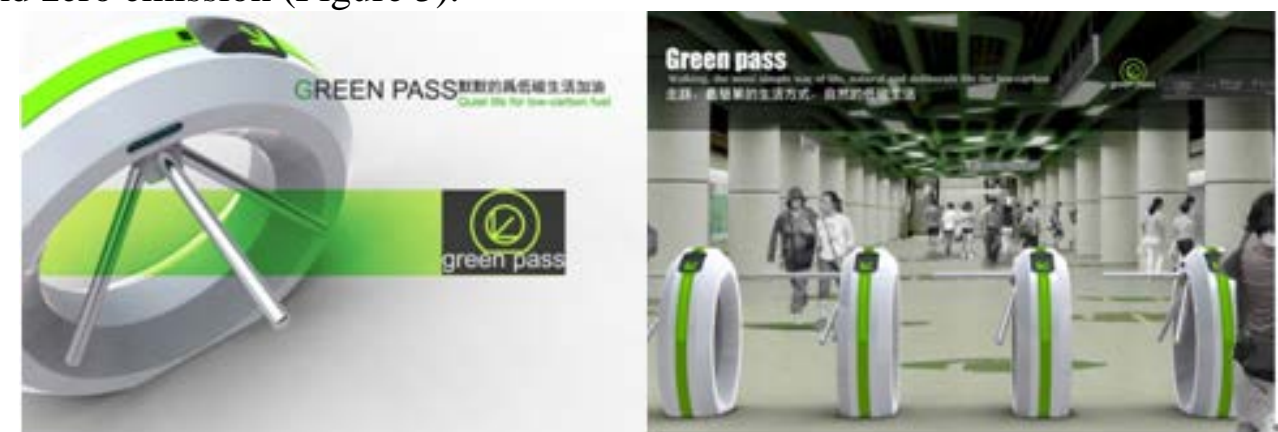

Fig 5. Green Pass (Three-Roll Pass)

\section{Summary}

Resource analysis provides a better approach to problems in product design. An analysis of resources within and beyond a system can greatly facilitate design of products with the least possible consumption of resources. Choose resources already available in a system as much as possible, as this will save resources and costs. This idea is also in line with the worldwide efforts in energy-conservation, environment-protection, and use of renewable energy.

\section{Acknowledgments:}

Foundation Item: Guangzhou Science and Technology Project (No. 2013Y2-00103);

GuangdongProvincial Training ProjectforExcellent Creative Young Teachersin Colleges andUniversities (No. 12ZK0092)

\section{References}

[1] Jones E, Harrison D. Investigating the use of TRIZ in Eco-innovation[J]. The TRIZ Journal, 2000: 65-69.

[2] Altshuller G, Shulyak L, Rodman S. 40 Principles: TRIZ keys to innovation[M]. Technical Innovation Center, Inc., 1997.

[3] Fey V, Rivin E. Innovation on demand: new product development using TRIZ[M]. Cambridge University Press, 2005.

[4] Thorsteinsson G, Page T, Vismantiene R. The Application of TRIZ in Product Design[J]. Dizainas, KurybaIrNaujosiosTechnologijos, 2008: 71-74.

[5] Johnson C J, Nielsen S E, Merrill E H, et al. Resource selection functions based on use-availability data: theoretical motivation and evaluation methods[J]. Journal of wildlife Management, 2006, 70(2): 347-357.

[6] Kenny D, Cao Q L, Kavinsky C, et al. Innovative resource utilization to fashion individualized covered stents in the setting of aortic coarctation[J]. Catheterization and Cardiovascular Interventions, 2011, 78(3): 413-418.

[7] Funk J L, Vitousek P M. Resource-use efficiency and plant invasion in low-resource systems[J]. 
Nature, 2007, 446(7139): 1079-1081.

[8] Wondolleck J M, Yaffee S L. Making collaboration work: Lessons from innovation in natural resource managment[M]. Island Press, 2000. 